\title{
Leber's hereditary optic neuropathy: the clinical relevance of different mitochondrial DNA mutations
}

\author{
Paul Riordan-Eva, Anita E Harding
}

Leber's hereditary optic neuropathy (LHON) was first described in 1858 by von Graefe. ${ }^{1}$ It was later named after Theodore Leber in recognition of his paper published in von Graefe's Archives of Ophthalmology in $1871 .^{2}$ Characteristically the disease presents in the second or third decades of life as a subacute optic neuropathy, developing sequentially in the two eyes, with vision reduced to worse than $6 / 60$, large central visual field defects, poor colour vision, and little recovery of vision. The importance of LHON lies in its ability to cause such severe and usually permanent visual loss in generally fit young people who are about to start or have recently begun employment or higher education, and the ramifications of diagnosing an inherited disease to other members of the patient's family. The recent discovery of various mutations of mitochondrial DNA in families with LHON has provided both an important diagnostic tool and also a means to improve our ability to determine prognosis and to understand the pathogenesis of the disease.

\section{The inheritance of LHON}

Leber recognised the two unusual features of the inheritance of LHON: maternal transmission and the propensity to affect males. Many theories have been proposed to explain the maternal inheritance pattern. Imai and Moriwaki ${ }^{3}$ first suggested cytoplasmic inheritance in 1936 and Erikson ${ }^{4}$ suggested a mutation of mitochondrial DNA (mtDNA) in 1972. In 1988 Wallace et $a l^{5}$ identified a mutation at base pair (bp) 11778 of mitochondrial DNA that is exclusively found in families with LHON.

Subsequently many mutations of $\mathrm{mtDNA}$ have been reported in LHON but the pathogenic significance of several of them is disputed.

\section{Evaluating the pathogenicity of mtDNA} mutations in LHON

All the mutations so far identified in LHON are point mutations of $\mathrm{mtDNA}$. They are generally detected by amplification of the relevant region of mtDNA and digestion by a restriction enzyme, for which the mutation causes loss or gain of a site. The criteria which are applied to establish the pathogenicity of individual mutations include the following.

(1) Identification of the mutation in a number of families known to have LHON, preferably families of independent origin with large well documented pedigrees showing a clear pattern of maternal transmission.

(2) Identification of the mutation exclusively in affected families and not in either normal controls or subjects with other types of optic neuropathy. Such a mutation is referred to as a primary mutation.

(3) The mutation should not coexist with other known pathogenic mutations.

(4) The mutation should be heteroplasmic in some people from affected families, as heteroplasmy does not seem to be a feature of harmless polymorphisms.

(5) The mutation should change a highly conserved amino acid residue.

The criteria are not absolute but the more criteria that are fulfilled the more certain the pathogenicity of the mutation under consideration.

\section{The mtDNA mutations in LHON}

The causative role for the Wallace mutation, which is the most commonly identified mutation in LHON families from Europe, the USA, Japan, and Australia, was originally established by identification of the mutation in two different pedigrees with LHON, one of an American black family and the other of a European white family. ${ }^{6}$ The mutation is not found in controls and it is heteroplasmic in certain subjects. The mutation results in substitution of histidine for a highly conserved arginine in the structure of NADH dehydrogenase (ND 4) in the complex I subunit of the mitochondrial respiratory chain. Both arginine and histidine are basic amino acids and thus this substitution is relatively conservative. A reduction in complex I activity has been shown in people with the 11778 mutation but only to the level found in smokers without the mutation. ${ }^{7}$ The 11778 mutation is not found in other optic neuropathies, such as anterior ischaemic optic neuropathy.

Other primary mutations, found exclusively in LHON families, include the mutations at 
bp $3460,14484,4160,4136$, and $5244 . .^{8-12}$ All of these mutations also result in amino acid changes in complex I polypeptides. The 3460 and 14484 mutations are now generally accepted as causative, having also been found exclusively in multiple LHON families of independent origin, and always being associated with the same clinical disorder. The recognition of the 14484 mutation as being of pathogenic importance was delayed because it only produces a conservative amino acid substitution (valine for methionine) in a relatively poorly conserved residue of the ND6 subunit of complex I. The 3460 mutation results in a substitution of a hydrophilic threonine for a hydrophobic alanine at a highly conserved residue in the ND1 subunit of complex I. Both the 3460 and 14484 mutations are found in the absence of other primary and secondary mutations and both are associated with changes in complex I activity. About $90 \%$ of patients with LHON worldwide carry either the 11778 , 3460 , or 14484 mutations. $^{13}$

The mutations at 4160 and 4136 were identified in a single family from Australia. ${ }^{11}$ It was suggested that the mutation at 4160 was the primary mutation and that the mutation at 4136 influenced the clinical syndrome, the family being characterised by unusual neurological features (see below). It has now been shown that this family also has the 14484 mutation, ${ }^{14}$ which is more likely to be the primary pathogenic mutation with respect of the optic nerve disease. The mutation at 5244 was also identified only in a single pedigree from the USA. $^{12}$ It is heteroplasmic and affects a conserved region of the ND2 subunit of complex I. A mutation at $\mathbf{1 3 7 3 0}$ has been identified, in the absence of other previously described primary or secondary LHON mutations, in one person with clinical findings consistent with LHON but without a family history. The mutation was not present in any other members of the family, even the mother. ${ }^{15}$ The mutation was heteroplasmic and results in a substitution of glutamic acid for glycine in what is thought to be an extramembrane hydrophobic domain of the ND5 protein of complex I.

Numerous mutations have been identified that occur in both LHON and control families but possibly at a higher frequency in the former. ${ }^{101216-20}$ These secondary mutations are often found in association with other secondary or primary mutations, making it difficult to assess their significance. It has been suggested that in the absence of one of the three major primary pathogenic mutations $(11778,3460$, or 14484) LHON only occurs if there are multiple secondary mutations, and that if a primary pathogenic mutation is present then the coexistence of secondary mutations will affect the disease manifestations. ${ }^{121621}$ Normal mtDNA is highly polymorphic and thus these theories are difficult to validate or refute directly.

The secondary mutations include the mutation at bp 15257 which produces a substitution of asparagine for a highly conserved aspartate in apocytochrome $b$ of complex III, resulting in a conformational change in a haem binding site. The mutation has been homplasmic in all cases tested, is found in $0.3 \%$ of normal controls, and is very frequently found in association with the 13708 or the 14484 mutations. ${ }^{1222}$ A study from the Netherlands of three pedigrees with LHON and the 15257 mutation showed that in each of the pedigrees either the 11778,3460 , or 14484 mutation was also present and that the 15257 mutation did not influence the clinical features or the probability of the development of LHON. ${ }^{23}$ A North American study of patients with LHON and the 15257 mutation found a $42 \%$ prevalence of spinal cord and peripheral neurological symptoms, although the aetiology of these symptoms was not investigated. ${ }^{24}$

The 15257 mutation has also been associated with retinal pigment epithelial disease, said most closely to resemble the inherited retinal dystrophy Stargardt's disease. ${ }^{25}$ Three affected patients were reported of whom one also had the 14484 mutation. The sister of the patient with both mutations developed unilateral visual loss for which the diagnosis of LHON was considered. Otherwise no details were provided as to the existence of a family history of visual loss or of any similar retinal changes in other relatives of the three probands.

The 13708 mutation produces a substitution of threonine for alanine in ND5 of complex I. ${ }^{16}$ It is found in up to $8 \%$ of normal controls and is likely to be a common northern European polymorphism. ${ }^{26}$ Assessing the significance of the secondary mutations is complicated by differences in their prevalence around the world. For instance the 9438 mutation is found in up to $18 \%$ of Africans but less than $0.05 \%$ of controls from non-African backgrounds. ${ }^{27} 28$. The detection of any of these secondary mutations cannot be used to make a diagnosis of LHON.

\section{Male predominance in $\mathrm{LHON}$}

The predominance of males among affected subjects with LHON is still unexplained. The concept of an $\mathrm{X}$ linked visual loss susceptibility gene was suggested by linkage studies ${ }^{29}$ but its existence was not confirmed by other authors ${ }^{30}$ and has now been refuted by reassessment of the original data. ${ }^{31}$

\section{The relevance of mtDNA mutations in LHON}

The identification of mtDNA mutations in LHON has led to a major reappraisal of the disease. In this respect it is imperative that the diagnostic significance of the various mutations is understood if this reappraisal is to be worthwhile, and if incorrect diagnoses with their undesirable consequences to other members of the family are to be avoided. Before the availability of mtDNA testing, diagnosis of LHON was based upon clinical findings, when possible supported by a family history, and the exclusion of other causes of optic neuropathy. Now the identification in a patient with an optic neuropathy of one of the primary pathogenic mutations, at bp 11778,3460 , or 14484 , 
virtually establishes the diagnosis whether there is a family history or not. Occasionally false positive results are obtained, as a result of non-pathogenic polymorphisms occurring very close to the mutation being investigated and coincidentally changing the relevant restriction site. ${ }^{32}$ Consideration should also be given to whether other factors have precipitated the onset of visual loss, as will be discussed later. Difficulty arises when the patient with an optic neuropathy is found to have one or more secondary mutations. Most clinicians would regard this as a negative result and rely on the clinical picture and the presence of a family history to diagnose LHON.

\section{Clinical spectrum of LHON}

The availability of mitochondrial DNA studies has emphasised that LHON may present from the first to the seventh decade of life, may be unilateral, may be associated with significant recovery of vision, and may be associated with neurological disease. All these relatively uncommon features have been identified previously in family studies but when they manifest in isolated cases the diagnosis of LHON is now much easier to substantiate. It is also apparent that the diagnosis of LHON can easily be missed in isolated cases if factors point to other diagnoses. For example a history of heavy alcohol and tobacco consumption may lead to a diagnosis of tobacco/alcohol amblyopia. The greater accessibility to and use of mtDNA testing in the investigation of optic neuropathies should reduce the risk of such misdiagnosis.

Of increasing interest to clinicians is the potential for correlating disease manifestations with particular mutations. A number of reports of the clinical manifestations in families with the three primary pathogenic mutations have now been published. ${ }^{222333-37}$ There is relatively little difference in most of the features of LHON between patients possessing the three primary pathogenic mutations. Men are more commonly affected than women, in a ratio of about $3: 1$. Only about $50 \%$ of index cases have an appropriate family history. The mean age at onset of visual loss is in the third decade of life. Virtually all patients suffer bilateral symmetrical visual loss with the two eyes being affected sequentially in about $50 \%$, the median delay between the two eyes being affected in such cases ranging from 6 to 22 weeks. Usually vision declines in each eye over a period of eight to 16 weeks with the visual acuity falling to counting fingers only.

\section{The ocular fundus in LHON}

LHON is associated with characteristic although not entirely specific fundal abnormalities. ${ }^{23-40}$ The small superficial vessels in the retina adjacent to the optic disc appear dilated and telangiectatic. The retinal nerve fibre layer in the peripapillary region appears swollen as may the optic disc itself. On fluorescein angiography there is no leakage of dye from the optic disc, in comparison to most causes of acquired optic disc swelling in which fluorescein leakage from the optic disc is an early feature. Also there is no leakage of dye from the retinal vessels.

Fundal abnormalities were reported to be universal in the acute phase of LHON such that their absence was said to exclude the diagnosis. ${ }^{40}$ Now it is clear that the fundal abnormalities are frequently not present ${ }^{33}$ and this may be particularly the case in the 14484 and 3460 mutation groups. ${ }^{225}$

The pathogenesis of the fundal abnormalities in LHON is unclear. It has been suggested that they indicate a primary retinal microvascular disorder but they may also be a non-specific response to changes within the retinal nerve fibre layer or within the anterior optic nerve. Also very similar features may be seen in the fundi of normal children and teenagers. Consequently no conclusions can yet be drawn about the relevance of the possibile paucity of fundal changes in LHON not associated with the Wallace mutation, except that it is likely to hinder the diagnosis being made in such cases.

\section{Visual outcome in LHON}

The most important and very consistent finding of recent publications is that the 14484 mutation is associated with a much better, and indeed relatively good, prognosis for vision. Studies from Australia, the USA, and the Netherlands have documentated a significant rate of recovery of vision among LHON patients with the 14484 mutation. ${ }^{223637}$ Fifty per cent of patients in these three series recovered vision and the overall median final visual acuity in the better eye was $6 / 24$ compared to $3 / 60$ for the 11778 and 3460 mutation groups. Furthermore a younger age of onset of visual loss, for practical purposes before the age of 20 , is strongly correlated with a better visual outcome. Among 14 patients at the National Hospital with LHON and the 14484 mutation for whom follow up at more than 24 months from the time of onset of visual loss is available, $50 \%$ have recovered vision to $6 / 24$ or better in the better eye. Six out of seven with onset of visual loss before 20 years of age have a final visual acuity of $6 / 9$ or better in the better eye, which should allow the possession of a standard British driving licence (Riordan-Eva et al, submitted). The better visual outcome in the 14484 mutation group is clearly because of visual recovery and not relatively mild disease from the outset. This recovery does not occur for many months or even years after the initial visual loss, and usually more than one year from the onset. The 3460 mutation may also be associated with a better visual outcome than the 11778 group but this has not yet been firmly established. ${ }^{35}$

\section{Mechanism of optic neuropathy in LHON}

Histopathological studies of LHON, carried out several years after the onset of visual loss, showed both axonal degeneration and myelin pallor involving the whole of the anterior visual pathways to the lateral geniculate bodies. ${ }^{4142}$ 
As discussed above, the fundal abnormalities have been interpreted as indicating a primarily intraocular disorder but this is not generally accepted. The clinical features suggest involvement of the retinal ganglion cells and their axons within the retina and optic nerves, possibly with selective involvement of smaller cells and axons explaining the characteristic large central visual field defects. In some people the nature of the field defect indicated involvement of the optic chiasm, which was also suggested by the findings at surgical exploration. ${ }^{434}$ Electrodiagnostic studies have not as yet shown any specific features although further studies using pattern electroretinography (PERG) are warranted to explore the potential involvement of the retinal ganglion cells. MRI abnormalities were originally interpreted as indicating disease in the orbital portion of the optic nerve ${ }^{45}$ but this is now thought to be a non-specific sign of Wallerian degeneration and gliosis.

Before the identification of a mitochondrial DNA mutation in LHON, biochemical studies related to a possible abnormality of cyanide metabolism with its potential relationship to cigarette smoking, which has been implicated in the precipitation of visual loss in the disease. Plasma cyanocobalamin concentrations were found to be raised in LHON patients, compatible with an inborn error of cyanide metabolism. ${ }^{46}$ Plasma and urinary levels of thiocyanate, the product of the detoxification of cyanide by the enzyme rhodanese (thiosulphate sulphur transferase), were found to be lower in LHON patients who smoked compared to control smokers. ${ }^{47}$ Measurement of rhodanese activity has produced conflicting results with some studies showing reduced levels in liver and rectal mucosa and others showing normal levels in liver and muscle. ${ }^{447-49}$ There is no definite evidence that patients with LHON have been exposed to excessive cyanide levels, even through cigarette smoking, and the role of cyanide intoxication in the causation of isolated optic nerve disease is disputed.

The identification of mtDNA mutations in LHON has shifted interest towards functional abnormalities of the mitochondrial respiratory chain. As discussed above, all the mtDNA mutations identified as of primary pathogenic importance in LHON families, and most of the the other mutations, produce changes in the structure of components of complex I of the mitochondrial respiratory chain. In the Australian family with the 14484 and $4160 \mathrm{bp}$ mutations a deficiency of complex I activity, as measured by rotenone sensitive NADH-CoQ reductase activity, was found in platelets of affected members. ${ }^{50}$ Reductions in complex I activity have been reported in muscle and isolated platelet mitochondria of both affected and unaffected members of families with the 11778 bp and the 3460 bp mutations. ${ }^{5152}$ In the 11778 mutation group the mild reduction (approximately $10 \%$ ) was equivalent to that found in smokers without the mutation but the deficiency is more marked with the 3460 mutation. Thus the presence of a mitochondrial DNA mutation is associated with reduction in complex I activity but there is not a clear correlation with development of visual loss.

There has been continuing interest in the relationship between tobacco and excessive alcohol consumption in the precipitation of visual loss in LHON. There are certain similarities in the clinical features of LHON and the optic neuropathy seen in tobacco/alcohol amblyopia, and it has been suggested that among LHON patients there is a greater than normal prevalence of tobacco and alcohol consumption, although this has not been formally substantiated. Among the 56 adult patients with LHON at the National Hospital for whom a tobacco and alcohol history was available, $11 \%$ of those with the 11778 mutation, $58 \%$ with the 14484 mutation, and $50 \%$ with the 3460 mutation consumed both tobacco and large amounts (more than 40 units per week) of alcohol but these data were not controlled (Riordan-Eva et al, submitted).

The true relationship between optic nerve disease and tobacco/alcohol abuse is still debated. Patients with the syndrome known as tobacco/alcohol amblyopia are usually very poorly nourished and vitamin deficiency, principally of members of the B vitamin group such as $\mathrm{B} 12$ and $\mathrm{B} 1$, which is known to cause optic nerve disease, may be a more important aetiological factor. The one published study that looked for the three primary pathogenic mtDNA mutations in patients with tobacco/ alcohol amblyopia found a mutation in two out of $12(17 \%)$ patients. ${ }^{53}$ One patient had the 11778 mutation and one the 3460 mutation. Neither patient had a family history of LHON. Their clinical features did not appear to differ significantly from the patients without the LHON mutations.

Further studies are needed to examine the relevance of tobacco and alcohol consumption to the pathogenesis of visual loss in LHON, particularly whether patients with LHON do smoke and drink more than their unaffected maternal relatives and whether any susceptibility to tobacco, alcohol, or vitamin deficiencies may differ from one mutation group to another. In the mean time it seems prudent to advise subjects at risk of developing LHON that tobacco smoking and heavy alcohol consumption should be avoided.

The clinical significance of heteroplasmy Heteroplasmy, the presence of a mixture of normal and mutant mtDNA, is commonly found in leucocytes from LHON patients and their unaffected relatives. Usually there are only trace amounts of normal mtDNA, but about $14 \%$ of patients and unaffected relatives with the 11778 mutation exhibit more obvious heteroplasmy. ${ }^{54}$ There is variability in the degree of heteroplasmy between families and between different generations of the same family. Rapid changes from very low proportions of mutant DNA to almost complete homoplasmy for mutant DNA can occur within two or three generations. ${ }^{556}$ Heteroplasmy may be a phase in the establishment of a pathogenic mutation.

Heteroplasmy has been implicated as the 
basis for the incomplete penetrance in LHON, ${ }^{54}$ only about $50 \%$ of males and about $10 \%$ of females possessing a primary pathogenic mutation suffering visual loss, and the variability in severity of visual loss among members of the same family. ${ }^{5758}$ Although visual loss is more likely if the patient is homoplasmic for mutant DNA, the correlation between the degree of heteroplasmy and the ophthalmological features is not good. For example many people who are homoplasmic for mutant DNA do not suffer visual loss. This may be a reflection of discrepancies between the degree of heteroplasmy in leucocytes and that in the optic nerve and retina, ${ }^{59}$ although this seems relatively unlikely.

\section{LHON and neurological disease}

An association between a maternally inherited optic neuropathy identical to LHON and other neurological disease has long been recognised. The associated neurological diseases include multiple sclerosis, Charcot-Marie-Tooth disease, and dystonic syndromes. ${ }^{60-62}$ In 1992 Harding et al $^{63}$ reported six patients, all females, with the 11778 bp mutation, who presented with bilateral optic neuropathy and a family history consistent with LHON, and later developed a multiple sclerosis-like illness according to clinical, MRI, and CSF findings. The combination of LHON and a multiple sclerosis-like illness has also been reported in one male patient with the 11778 bp mutation ${ }^{64}$ and two women with the 3460 mutation. ${ }^{26}$

The risk of women with the 11778 mutation developing a multiple sclerosis-like illness has not been defined prospectively. At the National Hospital, among 11 women with LHON and the 11778 mutation (including three of the patients reported by Harding et $a l^{63}$ ) five had a multiple sclerosis-like illness (Riordan-Eva et al, submitted).

This association between multiple sclerosis and LHON has prompted speculation about the role of immunological factors in the pathogenesis of LHON ${ }^{65}$ Systemic steroid therapy does not appear to have any benefit in LHON. Whether other forms of immunological therapy will be helpful in improving vision or preventing second eye involvement has yet to be determined.

The Australian family from Queensland with the 14484,4160 , and 4136 mutations appears to be unique in being associated with both a subacute infantile encephalopathy and other neurological abnormalities including tremor, ataxia, dysarthria, posterior column signs, and spasticity. ${ }^{66}$ The aetiology of these various neurological features is not clear but the encephalopathy does resemble Leigh's syndrome, which has been reported in association with other mutations of mtDNA. ${ }^{67}$ This encephalopathy apparently has occurred very infrequently, if at all, since the original description in $1970 .{ }^{14} \mathrm{~A}$ mutation at bp 4160 of mtDNA, which results in the substitution of proline for a highly conserved leucine and disruption of a small alpha helix in a hydrophilic loop of the ND1 protein, was reported in this kindred. ${ }^{11}$
It was also suggested that the mutation at $\mathrm{bp}$ 4136 , present in some but not all branches of the family, which produces a substitution of cysteine for tyrosine within the ND1 protein, acted as an intragenic suppressor mutation, ameliorating the neurological abnormalities. Subsequently this kindred was found to have the 14484 mutation. ${ }^{14}$ The ophthalmological features in this family resemble those of other families with the 14484 mutation, with a relatively good visual prognosis and a correlation between good visual outcome and an early onset of visual loss. Interestingly all males appear to develop some degree of visual loss. The neurological features still seem to be associated with the presence of the 4160 mutation. A large pedigree showing maternal transmission of variable features, including a LHON-like optic neuropathy and dystonia, was recently identified as having a mutation at position $14459 .{ }^{68}$

\section{LHON and cardiac disease}

Electrocardiographic abnormalities that have been associated with LHON include pre-excitation syndromes in eight pedigrees reported from Finland, ${ }^{69}$ prolonged Q-T invervals in an American black family with the 11778 mutation, ${ }^{70}$ and a combination of deep $Q$ waves and tall $R$ waves in the anterior chest leads in two patients reported from England. ${ }^{71}$ Information on the relative prevalence of electrocardiographic abnormalities between the three primary pathogenic mutations groups has not been published.

\section{Genetic counselling}

Genetic counselling in LHON is not straightforward as transmission of a mutation is not always associated with transmission of the disease. Although mtDNA heteroplasmy may be a factor determining penetrance of the disease, ${ }^{57}$ most patients and their unaffected relatives from LHON families have very high amounts of mutant mtDNA (>95\%), and many males at risk remain unaffected in this context. For this reason, analysis of mtDNA in relatives at risk is not very useful, particularly in young males at risk. Finding homoplasmy for the relevant mtDNA mutation, the most likely result, serves largely to confirm maternity and nearly always enhances family anxieties, even if the likelihood of this outcome is explained beforehand. This particularly applies to testing children, which is also dubious from the ethical point of view and thus best avoided. Although it is possible that some affected males may represent fresh mutations, which would be suggested by absence of the mutation in their mothers and other matrilineal relatives, this has only been described for the recently identified 13730 mutation which is of uncertain pathogenetic significance. ${ }^{15}$ It seems reasonable to analyse mtDNA in female relatives who seek genetic advice, partly for this theoretical possibility, and also because they may be at lower risk of transmitting the disease if they have substantial $(>30 \%)$ proportions of normal mtDNA. However, this is again more theor- 
etical than proven, and heteroplasmy in blood may not reflect the situation in their ocytes.

There have been no published data concerning recurrence risks in genetically defined LHON, and it is not clear whether they vary, depending on the mutation. Preliminary analysis of 87 LHON pedigrees with the 11778 (most common), 3460, and 14484 mutations studied at the National Hospital suggests risks of $34,14,42,9,40$, and $2 \%$ to the brothers, sisters, nephews, nieces, and male and female first cousins of patients respectively (Harding and Riordan-Eva, unpublished data). These risks can be modified taking age related penetrance into account; the median age at onset for all three mutations is approximately 20 years for males and 28 years for females, ranging from 3 to 65 years.

The difficulties referred to above in the use of mtDNA analysis in relatives at risk also apply to molecular genetic prenatal diagnosis. As it is not known what proportion of mutant mtDNA in chorionic villus material reduces the genetic risk, or whether this proportion may change during pre-and postnatal development, the only option for female carriers who wish to avoid a high risk pregnancy is abortion of male fetuses. However, the daughters of these women have a tangible risk of being affected and some may choose alternatives such as in vitro fertilisation of donated ova.

\section{The future}

The development of mtDNA testing for LHON has made an immense difference to the certainty with which the diagnosis can be made in subjects without a family history, in women, and in patients with atypical optic neuropathies. There has been a very useful re-evaluation of the clinical spectrum of the disease, which has actually led to very little change in the conclusions of previous family studies. The plethora of mtDNA mutations identified in families in LHON has resulted in confusion as to the pathogenic significance of each mutation, but it has been established that the three primary mutations at bp 11778,3460 , and 14484 are present in at least $90 \%$ of families with LHON. The correlation between the 14484 mutation and a good visual prognosis not only provides hope for affected patients, but an avenue for further research into the pathogenesis of LHON. Hopefully this will direct research into methods to prevent and treat the disease.

1 von Graefe A. Ein ungewöhnlicher Fall von hereditäre Amaurose. Graefes Arch Ophthalmol 1858;4:266-8.
Leber T. Ueber hereditäre und congenital-angelegte Sehner2 Leber T. Ueber hereditäre und congenital-angelegte Seh venleiden. Graefes Arch Ophthalmol 1871;17:249-91.
Imai Y, Moriwaki D. A probable case of cytoplasmic in heritance in man. A critique of Leber's disease. 7 Gene Hum 1936;3:163-7.

4 Erikson RP. Leber's optic atrophy: a possible example of mitochondrial inheritance. Am $\mathcal{f}$ Hum Genet 1972;24 $348-9$.

5 Wallace DC, Singh G, Lott MT, et al. Mitochondrial DNA mutation associated with Leber's hereditary optic neuropathy. Science 1988;242:1427-30.

6 Singh G, Lott MT, Wallace DC. A mitochondrial DNA mutation as a cause of Leber's hereditary optic neuropathy. $N$ Engl f Med 1989;320:1300-5.

7 Smith PR, Cooper JM, Govan GG, Harding AE, Schapira AHV. Platelet mitochondrial function in Leber's hereditary optic neuropathy. $\mathcal{f}$ Neurol Sci 1994;122:6-14.

8 Huoponen K, Vilkki Jula P, Nikoskelainen EK, Savontaus ML. A new mtDNA mutation associated with Leber hereditary optic neuroretinopathy. Am f Hum Genet 1991; 48:1147-53

9 Howell N, Bindoff LA, McCullough DA, et al. Leber hereditary optic neuropathy: identification of the same mitochondrial ND1 mutation in six pedigrees. Am $\mathfrak{f} \mathrm{Hum}$ Genet 1991;49:939-50.

10 Johns DR, Neufeld MJ, Park RD. An ND-6 mitochondrial DNA mutation associated with Leber hereditary optic neuropathy. Biochem Biophys Res Commun 1992;187:15517 .

11 Howell N, Kubacka I, Xu M, McCullough DA. Leber hereditary optic neuropathy: involvement of the mitochondrial ND1 gene and evidence for an intragenic supchondrial ND1 gene and evidence for an intragenic sup-

12 Wallace DC, Brown MD, Lott MT, Voljavec AS, Torroni A, Yang CC. Multiple mitochrondrial DNA mutations associated with Leber's hereditary optic neuropathy. Cytogenet Cell Genet 1991;58:2121.

13 Newman NJ. Leber's hereditary optic neuropathy. New genetic considerations. Arch Neurol 1993;50:540-8.

14 Mackey DA. Three subgroups of patients from the United Kingdom with Leber hereditary optic neuropathy. Eye 1994;8:431-6.

15 Howell N, Halvorson S, Burns J, McCullough DA, Poulton $\mathrm{J}$. When does bilateral optic atrophy become Leber herJ. When does bilateral optic atrophy become Leber her-

16 Johns DR, Berman J. Alternative simultaneous complex I mitochondrial DNA mutations in Leber's hereditary optic neuropathy. Biochem Biophys Res Commun 1991;174:132430.

17 Johns DR, Neufeld MJ. Cytochrome c oxidase mutations in Leber hereditary optic neuropathy. Biochem Biophys Res Commun 1993;196:810-15.

18 Huoponen $K$, Lamminen $T$, Juvonen V, Aula $P$, Nikoskelainen E, Savontaus ML. The spectrum of mitochondrial DNA mutations in families with Leber hereditary optic neuroretinopathy. Hum Genet 1993;92: 379-84

19 Brown MD, Yang CC, Trounce I, Torroni A, Lott MT, Wallace DC. A mitochondrial DNA variant, identified in Leber hereditary optic neuropathy patients, which extends Leber hereditary optic neuropathy patients, which extends
the amino acid sequence of cytochrome $\mathrm{c}$ oxidase subunit the amino acid sequence of cytochrom

20 Johns DR, Neufeld MJ. Cytochrome b mutations in Leber hereditary optic neuropathy. Biochem Biophys Res Commun 1991;181:1358-64.

21 Shoffner JM, Wallace DC. Mitochondrial genetics: principles and practice. Am $\mathscr{f}$ Hum Genet 1992;51:1179-86.

22 Johns DR, Heher KL, Miller NR, Smith KH. Leber's hereditary optic neuropathy. Clinical manifestations of the 14484 mutation. Arch Ophthalmol 1993;111:495-8.

23 Oostra RJ, Bolhuis PA, Zorn-Ende I, de Kok-Nazaruk MM, Bleeker-Wagemakers EM. Leber's hereditary optic neuropathy: no significant evidence for primary or secondary pathogenicity of the 15257 mutation. Hum Genet 1994; pathogenicity

24 Johns DR, Smith KH, Savino J, Miller NR. Leber's hereditary optic neuropathy. Clinical manifestations of the editary optic neuropathy. Clinical manifestations

25 Heher KL, Johns DR. A maculopathy associated with the 15257 mitochondrial DNA mutation. Arch Ophthalmol 1993;111:1495-9.

26 Kellar-Wood H, Robertson N, Govan GG, Compston DAS, Harding AE. Leber's hereditary optic neuropathy mitochondrial DNA mutations in multiple sclerosis. Ann Neurol 1994;36:109-12.

27 Brown MD, Torroni A, Huoponen K, Chen YS, Lott MT, Wallace DC. Pathological significance of the mtDNA COX III mutation at nucleotide pair 9438 in Leber hereditary optic neuropathy. Am 7 Hum Genet 1994;55:410.

28 Johns DR. Reply to Brown et al. Am $\mathcal{f}$ Hum Genet 1994;55: $410-12$.

29 Vilkki J, Ott J, Savontaus ML, Aula P, Nikoskelainen EK. Optic atrophy in Leber hereditary optic neuroretinopathy is probably determined by an X-chromosomal gene closely linked to DXS7. Am ₹ Hum Genet 1991;48:486-91.

30 Sweeney MG, Davis MB, Lashwood A, Brockington M, Toscano A, Harding AE. Evidence against an X-linked locus close to DXS7 determining visual loss susceptibility in British and Italian families with Leber hereditary optic neuropathy. Am $\mathcal{F}$ Hum Genet 1992;51:741-8.

31 Juvonen V, Vilkki J, Aula P, Nikoskelainen E, Savontaus ML. Reevaluation of the linkage of an optic atrophy susceptibility gene to X-chromosomal markers in Finnish families with Leber hereditary optic neuroretinopathy families with Leber hereditary optic neuror

32 Johns DR, Neufeld MJ. Pitfalls in the molecular genetic diagnosis of Leber hereditary optic neuropathy (LHON). diagnosis of Leber hereditary optic

33 Newman NJ, Lott MT, Wallace DC. The clinical characteristics of pedigrees of Leber's hereditary optic neuropathy with the 11778 mutation. Am $\mathcal{F}$ Ophthalmol 1991; 111:750-62.

34 Stone EM, Newman NJ, Miller NJ, Johns DR, Lott MT, Wallace DC. Visual recovery in patients with Leber's hereditary optic neuropathy and the 11778 mutation. $\mathcal{F}$ Clin Neuro-Ophthalmol 1992;12:10-14.

35 Johns DR, Smith KH, Miller NR. Leber's hereditary optic neuropathy. Clinical manifestations of the 3460 mutation. Arch Ophthalmol 1992;110:1577-81.

36 Mackey D, Howell N. A variant of Leber hereditary optic neuropathy characterized by recovery of vision and by an unusual mitochondrial genetic etiology. Am $7 \mathrm{Hum}$ Genet 1992;51:1218-28. 
37 Oostra RJ, Bolhuis PA, Wijburg FA, Zorn-Ende G, BleekerWagemakers EM. Leber's hereditary optic neuropathy: correlations between mitochondrial genotype and visual outcome. 7 Med Genet 1994;31:280-6.

38 Smith JL, Hoyt WF, Susac JO. Ocular fundus in acute Leber optic neuropathy. Arch Ophthalmol 1973;90:349-54.

39 Nikoskelainen E, Hoyt WF, Nummelin K. Ophthalmoscopic findings in Leber's hereditary optic neuropathy. The findings in Leber's hereditary optic neuropathy. The
fundus findings in affected family members. Arch Ophfundus findings in affected

40 Nikoskelainen E, Hoyt WF, Nummelin K, Schatz H. Fundus findings in Leber's hereditary optic neuroretinopathy. III. 102:981-9.

41 Wilson J. Leber's hereditary optic atrophy: some clinical and aetiological considerations. Brain 1963;86:347-62.

42 Adams JH, Blackwood W, Wilson J. Further clinical and pathological observations on Leber's optic atrophy. Brain 1966;89:15-26.

43 Imachi J. Über 50 hirnchirurgisch behandelte Fälle von Leberscher Opticusatrophie. Ber Deutsche Ophthalmologische Gesellschaft 1961;64:268-71.

44 Weinder NC, Newman NJ, Lessell S, Johns DR, Lott MT, Wallace DC. Atypical Leber's hereditary optic neuropathy with molecular confirmation. Arch Neurol 1993;50:470-3.

45 Kermode AG, Moseley IF, Kendall BE, Miller DH, MacManus DG, McDonald WI. Magnetic resonance imaging
in Leber's optic neuropathy. $\mathcal{F}$ Neurol Neurosurg Psychiatry in Leber's optic

46 Wilson J, Linnell JC, Matthews DM. Plasma-cobalamins in neuro-ophthalmological diseases. Lancet 1971;i:259-61.

47 Wilson J. Leber's hereditary optic atrophy: a possible defect of cyanide metabolism. Clin Sci 1965;29:505-15.

48 Nikoskelainen EK, Hassinen IE, Paljarvi L, Lang H, Kalimo H. Leber's hereditary optic neuroretinopathy, a mitochondrial disease? Lancet 1984;ii;1474.

49 Poole CJM, Kind PRN. Deficiency of thiosulphate sulphurtransferase (rhodanese) in Leber's hereditary optic neuropathy. $B M F$ 1986;292:1229-30.

50 Parker WD Jr, Oley CA, Parks JK. A defect in mitochondrial electron-transport activity (NADH-coenzyme $Q$ oxidoreductase) in Leber's hereditary optic neuropathy. $N$ Engl f Med 1989;320:1331-3.

51 Toscano A, Harding AE, Castagna I, et al. Familial Leber's hereditary optic neuropathy: morphology, biochemistry and genetics in blood

52 Larsson NG, Anderson O, Holme E, Oldfors A, Wahlstrom J. Leber's hereditary optic neuropathy and complex I deficiency in muscle. Ann Neurol 1991;30:701-8.

53 Cullom ME, Heher KL, Miller NR, Savino PJ, Johns DR. Leber's hereditary optic neuropathy masquerading as tobacco-alcohol amblyopia. Arch Ophthalmol 1993;111: 1482-5.

54 Smith KH, Johns DR, Heher KL, Miller NR. Heteroplasmy in Leber's hereditary optic neuropathy. Anch Ophthalmol 1993;111: 1486-90.

55 Bolhuis PA, Bleeker-Wagemakers EM, Ponne NJ, et al.
Rapid shift in genotype of human mitochondrial DNA in a family with Leber's hereditary optic neuropathy. Biochem Biophys Res Commun 1990;170:994-7.

56 Lott MT, Voljavec AS, Wallace DC. Variable genotype of Leber's hereditary optic neuropathy patients. $A m \mathcal{F}$ Ophthalmol 1990;109:625-31.

57 Holt IJ, Miller DH, Harding AE. Genetic heterogeneity and mitochondrial DNA heteroplasmy in Leber's hereditary optic neuropathy. $\mathcal{F}$ Med Genet 1989;26:739-43.

58 Isashiki $Y$ Nakagawa M. Clinical correlation of mitochondrial DNA heteroplasmy and Leber's hereditary optic chondrial DNA heteroplasmy and Leber's hereditar

59 Howell N, Xu M, Halvorson S, Bodis-Wollner I, Sherman J. A heteroplasmic LHON family: tissue distribution and transmission of the 11778 mutation. Am $\mathcal{F}$ Hum Genet 1994;55:203-6.

60 Lees F, MacDonald AM, Aldren Turner JW. Leber's disease with symptoms resembling disseminated sclerosis. $\mathcal{F}$ Neurol Neurosurg Psychiatry 1964;27:415-21.

61 McLeod JG, Low PA, Morgan JA. Charcot-Marie-Tooth disease with Leber optic atrophy. Neurology 1978;28:179-84.

62 Marsden CD, Lang AE, Quinn NP, McDonald WI, Abdallat A, Nimri S. Familial dystonia and visual failure with striatal CT lucencies. I Neuml Neurosurg Psychiatry 1986; 49:500-9.

63 Harding AE, Sweeney MG, Miller DH, et al. Occurrence of a multiple sclerosis-like illness in women who have a of a multiple sclerosis-like illness in women who have a mutation. Brain 1992;115:979-89.

64 Flanigan KM, Johns DR. Association of the 11778 mitochondrial DNA mutation and demyelinating disease. Neurology 1993;43:2720-2.

65 Harding SE, Sweeney MG. Leber's hereditary optic neuropathy. In: Schapira AHV, DiMauro S, eds. Mitochondrial disorders in neurology. London: Butterworth Heinemann, 1994.

66 Wallace DC. A new manifestation of Leber's disease and a new explanation for the agency responsible for its unusual pattern of inheritance. Brain 1970;93:121-32.

67 Hammans SR, Sweeney MG, Brockington M, MorganHughes JA, Harding AE. Mitochondrial encephalopathies: molecular genetic diagnosis from blood samples. Lancet 1991;337:1311-13.

68 Jun AS, Brown MD, Wallace DC. A mitochondrial DNA mutation at nucleotide pair 14459 of the NADH de-
hydrogenase subunit 6 gene associated with maternally hydrogenase subunit 6 gene associated with maternally inherited Leber hereditary optic neuropathy

69 Nikoskelainen E, Wanne O, Dahl M. Pre-excitation syndrome and Leber's hereditary optic neuropathy. Lancet 1985;i:696.

70 Ortiz RG, Newman NJ, Manoukian SV, Diesenhouse MC, Lott MT, Wallace DC. Optic disk cupping and electrocardiograpic abnormalities in an American pedigree with Leber's hereditary optic neuropathy. Am $\mathcal{F}$ Ophthalmol 1992;113:561-6.

71 Clifford Rose F, Bowden AN, Bowden PMA. The heart in Leber's optic atrophy. Br f Ophthalmol 1970;54:388-93. 